\title{
Intratumoral Accumulation and Clonal Expansion May Not Be Decisive for Rejection of Allogeneic Tumors by CD8+ T-Lymphocytes
}

\author{
JURGITA JURŠĖNAITE ${ }^{1}$, IRUTE GIRKONTAITE ${ }^{1}$, ALMANTAS ŠIAURYS ${ }^{1}$, \\ MYKOLAS MAURICAS ${ }^{1}$ and DAINIUS CHARACIEJUS ${ }^{1,2}$ \\ ${ }^{1}$ Department of Immunology, Centre for Innovative Medicine, Vilnius, Lithuania; \\ ${ }^{2}$ Department of Pathology, Forensic Medicine and Pharmacology, \\ Institute of Biomedical Sciences, Faculty of Medicine, Vilnius University, Vilnius, Lithuania
}

\begin{abstract}
Background: The aim of this study was to analyze the spatial distribution and proliferation of adoptively transferred $C D 8^{+}$T-lymphocytes sensitized against allogeneic tumors. Materials and Methods: Transgenic $\beta$-actin-luc mice that express luciferase were sensitized against allogeneic SL2 lymphoma. $C D 8^{+}$T-lymphocytes from these mice were transferred to lymphocyte-deficient, recombination activating gene-deficient $\left(\mathrm{Rag}^{-1-}\right)$ mice bearing SL2 tumors and were tracked using bioluminescence imaging. Results: Two out of six $\mathrm{Rag}^{-1-}$ mice rejected their tumors. There were no apparent differences in spatial distribution and proliferative intensity of adoptively-transferred $\mathrm{CD}^{+}{ }^{+}$T-lymphocytes between the two $\mathrm{Rag}^{-/-}$mice that rejected allogeneic SL2 tumors and the four Rag ${ }^{-1-}$ mice that did not. Conclusion: The pattern of distribution in the mouse body and proliferative intensity of $C D 8^{+}$T-lymphocytes do not seem to be decisive factors influencing allogeneic tumor rejection.
\end{abstract}

The prevailing view holds that cytotoxic T-lymphocytes kill tumor cells by a lytic mechanism requiring direct contact between T-lymphocytes and target tumor cells (1). If this lytic mechanism indeed operates in vivo, rejection of tumors by cytotoxic T-lymphocytes should always be preceded by expansion of a specific clone of $\mathrm{CD} 8^{+} \mathrm{T}$-lymphocytes and their migration to the tumor site. Migration of $\mathrm{CD} 8^{+}$ T-lymphocytes to tumors expressing human papillomavirusencoded oncogenic protein E7 (2), and chicken ovalbumin

Correspondence to: Professor D. Characiejus, Faculty of Medicine, Vilnius University, M.K. Čiurlionio 21, LT-03101 Vilnius, Lithuania. Tel: +370 52398728, Fax: +370 52398705, e-mail: dainius.characiejus@gmail.com

Key Words: Murine tumor model, CD8+ T-lymphocytes, adoptive transfer, bioluminescence imaging. and SV40 large T-antigen (3) has been observed using bioluminescence imaging. In our previous publication, using bioluminescence imaging, we demonstrated preferential accumulation of lymphocytes at the tumor site during rechallenge with allogeneic SL2 lymphoma cells after primary SL2 tumor has been rejected (4). Thus, bioluminescence imaging is a sensitive tool for detecting intratumoral accumulation of lymphocytes. In addition, measuring the total photon flux allows estimation of lymphocyte proliferation. In the present study, we analyzed the spatial distribution and proliferation intensity of $\mathrm{CD}^{+}$T-lymphocytes during challenge with primary allogeneic SL2 tumors.

\section{Materials and Methods}

Mice and tumors. Transgenic luciferase-expressing B6, FVB $\beta$ actin-luc female mice (Light Producing Transgenic Animals ${ }^{\circledR}$, Model 10500) were purchased from Taconic (Germantown, NY, USA). These mice are described in more detail in our previous publication (4). Transgenic $\beta$-actin-luc mice at the age of 10 months were sensitized against allogeneic SL2 tumor by subcutaneous injection on the left side of the chest of $1 \times 10^{6}$ tumor cells in phosphate-buffered saline (PBS).

CD8 + T-lymphocytes isolated from spleens of transgenic $\beta$-actinluc mice were transferred to 11-to 14-week-old lymphocytedeficient, recombination activating gene-deficient $\left(\mathrm{Rag}^{-/-}\right)$mice, bearing SL2 tumors. Rag-deficient ( $\mathrm{Ragl}^{-/-}$or $\mathrm{Rag}^{-/-}$) mice were a kind gift from Professor Reinhard Voll, University ErlangenNürnberg, Germany, and were bred at a local breeding facility at the State Research Institute Centre for Innovative Medicine, Vilnius, Lithuania. Experimental research on animals was conducted according to guidelines of the Lithuanian Ethics Committee for Laboratory Animal Use (approval no. 02-24).

SL2 lymphoma cells were maintained by weekly intraperitoneal passage in syngeneic DBA/2 mice and subsequently frozen. Prior to use in experiments, SL2 cells were thawed, washed and resuspended in RPMI-1640 medium. Solid tumors in $\mathrm{Rag}^{-/}$mice were induced by subcutaneous injection into the right side of the chest of $1 \times 10^{6}$ SL2 cells in PBS. 
Transgenic $\beta$-actin-luc mice (Model 10500) are of C57BL/6 (B6), FVB genetic background $\left(\mathrm{H} 2^{\mathrm{b}}\right.$ and $\mathrm{H} 2 \mathrm{q}$ haplotype, respectively), whereas SL2 tumor cells are of DBA/2 origin which carry $\mathrm{H}-2^{\mathrm{d}}$ haplotype. Thus, SL2 tumor cells are allogeneic to Tlymphocytes from transgenic $\beta$-actin-luc mice.

Isolation and transfer of $C D 8^{+}$T-lymphocytes. At 15 days after implantation of SL2 tumors, transgenic $\beta$-actin-luc mice were sacrificed by cervical dislocation, spleens were removed and singlecell lymphocyte suspensions were prepared by enzymatic digestion using Spleen Dissociation Kit in combination with mechanical dissociation using GentleMACS Dissociator (both from Miltenyi Biotec GmbH, Bergisch Gladbach, Germany). CD8+ T-lymphocytes from spleen cell suspension were separated using magnetic beadmediated negative selection using CD8 $\mathrm{a}^{+} \mathrm{T}$-Cell Isolation Kit, LS columns, and MidiMACS separator (Miltenyi Biotec $\mathrm{GmbH}$ ). Isolated CD8+ T-lymphocytes were transferred intravenously in PBS to SL2 tumor-bearing $\mathrm{Rag}^{-/-}$mice $\left(3.6 \times 10^{6}\right.$ cells per mouse) via retro-orbital injection on day 8 after implantation of tumors.

Bioluminescence imaging. Bioluminescence measurements in SL2 tumor-bearing $\mathrm{Rag}^{-/-}$mice were performed using IVIS ${ }^{\circledR}$ Spectrum equipment (Caliper/Perkin Elmer, Hopkinton, MA, USA) at 2, 4, 6, $8,20,14$ and 18 days after adoptive transfer of $\mathrm{CD} 8^{+} \mathrm{T}$-lymphocytes. Two-dimensional in vivo bioluminescence imaging using autoexposure mode was performed to evaluate the pattern of distribution of adoptively transferred $\mathrm{CD}^{+} \mathrm{T}$-lymphocytes in the mouse body. Three-dimensional imaging of the whole mouse body was carried out to estimate the total flux of photons per second, which is proportional to the number of living lymphocytes in vivo and thereby can be used to estimate lymphocyte proliferation and death. Data were acquired and analyzed using Living Image ${ }^{\circledR}$ software, version 4.3.1 (Caliper/Perkin Elmer). Details of bioluminescence imaging are described in our previous publication (4).

\section{Results}

Two out of six SL2 tumor-bearing $\mathrm{Rag}^{-/-}$mice rejected tumors after adoptive transfer of $\mathrm{CD} 8^{+} \mathrm{T}$-lymphocytes from transgenic $\beta$-actin-luc mice sensitized against allogeneic SL2 cells. The other four SL2 tumor-bearing $\mathrm{Rag}^{-/-}$mice died within 2 weeks after lymphocyte transfer (within 22 days after implantation of tumors).

Overlay of luminescent and light photographic images from tumor-bearing $\mathrm{Rag}^{-/-}$mice at 2, 6, 10 and 18 days after adoptive transfer of $\mathrm{CD} 8^{+}$T-lymphocytes is shown in Figure 1. These images demonstrate that T-lymphocytes were distributed in various parts of the mouse body. No preferential accumulation of lymphocytes at the tumor site was observed.

Total flux of photons from individual SL2 tumor-bearing $\mathrm{Rag}^{-/}$mice at different time points after the adoptive transfer of $\mathrm{CD}^{+} \mathrm{T}$-lymphocytes is shown in Figure 2. The average total photon flux increased from $1.11 \times 10^{7}$ photons per second on day 2 to $1.84 \times 10^{9}$ photons per second on day 10 . This means that the number of lymphocytes in the mouse body increased on average 166-foId during this 8 -day period.
However, the total photon flux curves of the two mice that rejected tumors did not differ until day 10 from those of the four mice that did not reject tumors. The total photon flux increased about 37 -fold from day 14 to 18 in the two mice that rejected tumors, showing proliferation of lymphocytes after tumor rejection.

\section{Discussion}

The tumor rejection rate in this study seemed to be lower compared to our previous results showing rejection of allogeneic SL2 tumors in six out of nine and in six out of six $\mathrm{Rag}^{-/-}$mice after adoptive transfer of sensitized spleen cells or T-lymphocytes, respectively (4). One explanation for the difference in tumor rejection rates between our previous and current results is that $\mathrm{CD} 4^{+}$lymphocytes are necessary for the antitumor effect $(5,6)$. Another possible explanation might be due to the fact that in this study middle-aged mice (10 months old) were used, whereas in the previous study, young mice (7-9 weeks old) were used as lymphocyte donors. It has been shown that the antitumor function of $\mathrm{CD} 8^{+} \mathrm{T}$-cells critically declines with age (7).

Whatever the cause of this relatively low rejection rate, the model described here allows comparison of the distribution of $\mathrm{CD}^{+} \mathrm{T}$-lymphocytes between mice that reject and mice that do not reject allogeneic tumors.

In this study, allogeneic tumors were rejected in two mice with no preferential intratumoral accumulation of $\mathrm{CD} 8^{+} \mathrm{T}$ lymphocytes and with lymphocyte proliferation similar to that seen in the four mice that did not reject tumors. This observation is somewhat in contrast to the reports of Kim et al. (2), Charo et al. (3) and to our previous publication (4). The differences may be explained by the fact Kim et al. (2) and Charo et al. (3) used foreign antigens to increase tumor immunogenicity. In our previous publication (4), we described accumulation of T-lymphocytes in secondary allogeneic tumors after primary tumors had been rejected. It can be hypothesized that in all these cases, more specific Tlymphocytes existed with higher capacities to accumulate within tumors.

Our current observation suggests that intratumoral accumulation and expansion of $\mathrm{CD} 8^{+} \mathrm{T}$-lymphocytes may not be decisive for rejection of allogeneic tumors. Direct contact between a sufficient number of specific $\mathrm{CD} 8^{+}$ T-lymphocytes and tumor cells would be necessary if tumor cells were killed by a cytotoxic mechanism. Thus, doubts can be raised whether direct cytotoxicity is the most important mechanism in the control of allogeneic tumor by $\mathrm{CD}^{+}$ T-lymphocytes. Our observation adds to the evidence from publications by other authors, suggesting existence of alternative mechanisms of tumor growth control by $\mathrm{CD} 8^{+}$ T-lymphocytes. Cole and Ostrand-Rosenberg described rejection of allogeneic tumor by $\mathrm{CD} 8^{+} \mathrm{T}$-lymphocytes that 


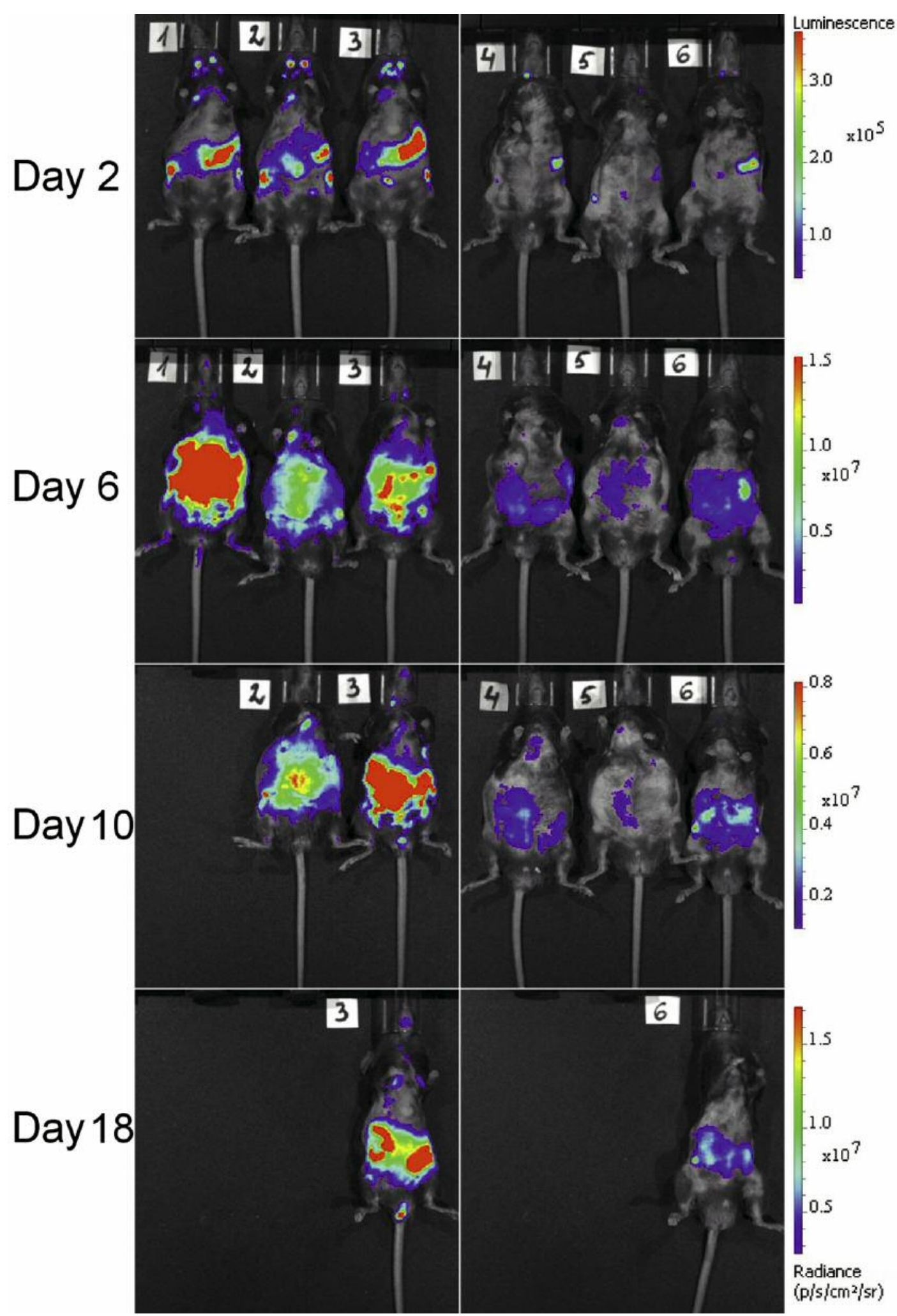

Figure 1. Overlay of luminescent and light photographic images from three female (left column) and three male (right column) SL2 tumor-bearing recombination-activating gene-deficient (Rag-/-) mice at 2, 6, 10 and 18 days after adoptive transfer of $3.6 \times 10^{6} \mathrm{CD}^{+} 8^{+}$-lymphocytes isolated from the spleen of transgenic $\beta$-actin-luc mice sensitized against SL2 cells. Tumors were induced by injecting $1 \times 10^{6}$ SL2 cells into the right side of the chest 8 days prior to adoptive transfer of lymphocytes. 


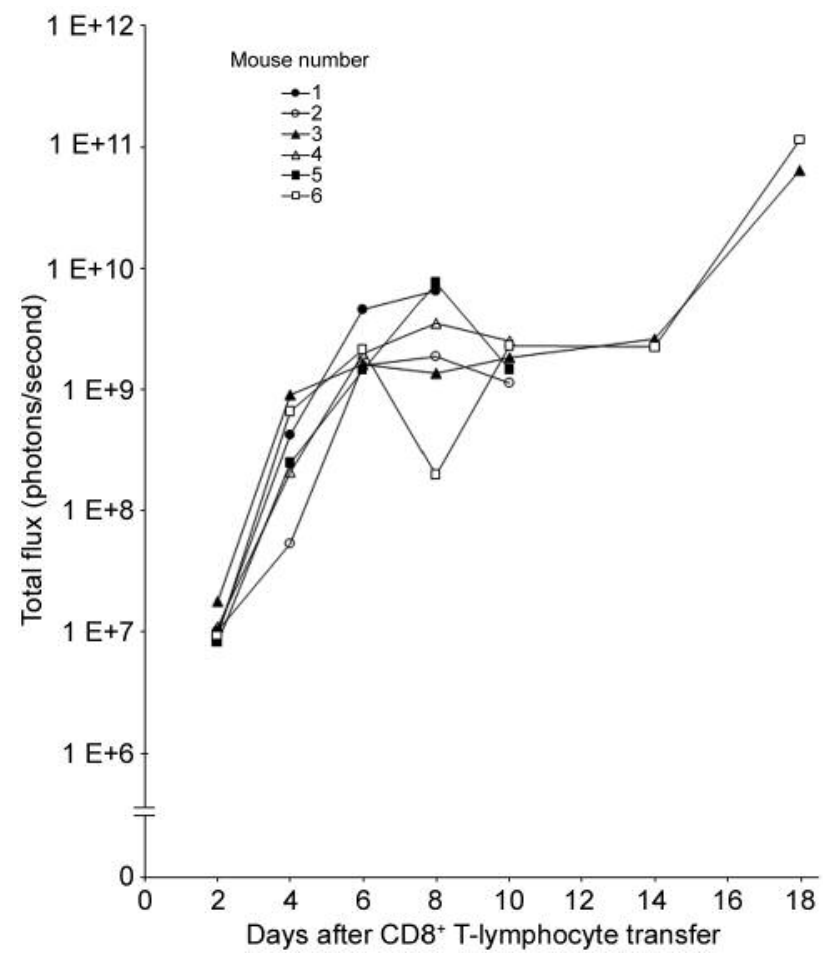

Figure 2. Total flux of photons from individual SL2 tumor-bearing recombination activating gene-deficient $\left(\mathrm{Rag}^{-1-}\right)$ mice at different time points after adoptive transfer of $3.6 \times 10^{6} \mathrm{CD} 8^{+} T$-lymphocytes isolated from the spleen of transgenic $\beta$-actin-luc mice sensitized against SL2 cells. Tumors were induced by injecting $1 \times 10^{6}$ SL2 cells into the right side of the chest 8 days prior to adoptive transfer of lymphocytes. Mouse numbers correspond to those in Figure 1.

were not lytic for the tumor (8). Karan et al. demonstrated that decreased cytotoxic T-cell activity in vitro was associated with augmented antitumor immunity in a mouse model (9). Elucidation of alternative mechanisms of tumor growth control by $\mathrm{CD}^{+}$T-lymphocytes might have important implications for cancer immunotherapy.

\section{Acknowledgements}

This research was funded by a Grant (no. MIP-046/2013) from the Research Council of Lithuania.

\section{References}

1 Halle S, Halle $\mathrm{O}$ and Förster R: Mechanisms and dynamics of T-cell-mediated cytotoxicity in vivo. Trends Immunol 38: 432443, 2017.

2 Kim D, Hung CF and Wu TC: Monitoring the trafficking of adoptively transferred antigen-specific CD8-positive T-cells in vivo, using noninvasive luminescence imaging. Hum Gene Ther 18: 575-588, 2007.

3 Charo J, Perez C, Buschow C, Jukica A, Czeh M and Blankenstein $\mathrm{T}$ : Visualizing the dynamic of adoptively transferred T-cells during the rejection of large established tumors. Eur J Immunol 41: 3187-3197, 2011.

4 Juršènaitė J, Girkontaitė I, Mauricas M, Eidukevičius R, Šiaurys A and Characiejus D: Bioluminescence imaging of adoptively transferred lymphocytes during allogeneic tumor rejection. Anticancer Res 35: 6573-6576, 2015.

5 Koido S, Enomoto Y, Apostolopoulos V and Gong J: Tumor regression by $\mathrm{CD} 4 \mathrm{~T}$-cells primed with dendritic/tumor fusion cell vaccines. Anticancer Res 34: 3917-3924, 2014.

6 Vanbuskirk A, Oberyszyn TM and Kusewitt DF: Depletion of $\mathrm{CD}^{+}$or $\mathrm{CD}^{+}$lymphocytes enhances susceptibility to transplantable ultraviolet radiation-induced skin tumours. Anticancer Res 25: 1963-1968, 2005.

7 Wheeler CJ, Black KL, Liu G, Ying H, Yu JS, Zhang W and Lee PK: Thymic CD8+ T-cell production strongly influences tumor antigen recognition and age-dependent glioma mortality. J Immunol 171: 4927-4933, 2003.

8 Cole GA and Ostrand-Rosenberg S: Rejection of allogeneic tumor is not determined by host responses to MHC class I molecules and is mediated by $\mathrm{CD} 4{ }^{-} \mathrm{CD} 8+\mathrm{T}-\mathrm{lymphocytes}$ that are not lytic for the tumor. Cell Immunol 134: 480-490, 1991.

9 Karan D, Krieg AM and Lubaroff DM: Paradoxical enhancement of CD8 T-cell-dependent antitumor protection despite reduced CD8 T-cell responses with addition of a TLR9 agonist to a tumor vaccine. Int J Cancer 121: 1520-1528, 2007. 